\title{
Extraction of Essential Oils from Pumpkin Seeds: RSM Based Process Modeling, Optimization and Oil Characterization
}

\author{
Ramesh Redrouthu, Venkatesa Prabhu Sundramurthy, Bekele Zergu
}

\begin{abstract}
The oils extracted from pumpkin seeds have been distinguished as good nutrient vegetable oil. This study aimed to study about the extraction of oils from pumpkin seed oils by Soxhlet method using ethanol as a solvent. The effect of process variables such as temperature, extraction time and particle size were aimed to optimize for maximizing the yield of seeds oil using response surface methodology (RSM). Optimization study showed that the maximum extracted crude oil yield (56.2\%) was obtained at extraction temperature of $75{ }^{\circ} \mathrm{C}$, extraction time of $270 \mathrm{~min}$ and particle size of $0.25 \mathrm{~mm}$. The process model was developed for relation between yield of oils and chosen the independent factors. At optimize condition the extracted oils were subjected to characterization. The interaction effect between different the selected process parameter were also investigated against oil extraction. In addition, the physico-chemical properties of the crude and refined oils obtained at optimum optimal condition were also determined. The FT-IR characterization on the extracted oils showed the presence of functional groups of carbohydrate, carbocyclic, alkane, carbonyl, alkene, aliphatic amine, aromatic, alcohol and methyl ester. The GC-MS characterization of the extracted oils was also investigated for fatty acids composition.
\end{abstract}

Keywords: Fatty acids, FT-IR, GC-MS, Pumpkin seed oils, RSM, Solvent extraction.

\section{INTRODUCTION}

Cucurbitaceae, also known as cucurbits, native to the Andes and Mesoamerica [1] are a plant family that consisting about 965 species with 95 genera. The most important genus of this family is Cucurbita. There are five species are grown worldwide as edible fruit including pumpkin. Pumpkin is one of the most nutritious fruits and has flavorful seeds. Pumpkins are usually orange, dark green, pale green, yellow, white and red. Pumpkins generally weigh from 4-8 kg. Pumpkin seeds have interesting organoleptic properties and are a rich source of biologically active substances such as sterols, squalene, carote noids and

Revised Manuscript Received on April 21, 2020

* Correspondence Author

Venkatesa Prabhu. S*, Chemical Engineering, Addis Ababa Science and Technology University, Addis Ababa, Ethiopia.

Ramesh Redrouthu, Chemical Engineering, Addis Ababa Science and Technology University, Addis Ababa, Ethiopia.

Bekele Zergu, Chemical Engineering, Addis Ababa Science and Technology University, Addis Ababa, Ethiopia.

(C) The Authors. Published by Blue Eyes Intelligence Engineering and Sciences Publication (BEIESP). This is an open access article under the CC BY-NC-ND license (http://creativecommons.org/licenses/by-nc-nd/4.0/) tocopherols. They are available year round [2,3]. Cucurbitaceae used as vegetable and medicine throughout the world [4-6]. Pumpkin fruit is physically composed of seed [7]. Pumpkin seeds are white or brown and are consumed directly by humans as a snack food [8]. The highest proportion of the pumpkin seed oil is composed of fatty acids. Test results of the fatty acids composition of the oil indicated the presence of unsaturated fatty acids (linoleic, oleic, palmitoleic and arachidic acid) and saturated fatty acids (palmitic and stearic acid). They are also called as essential oils that are aromatic liquids. Essential oils used for many purpose such as perfumes, cosmetics, lotion, food preservation, food flavors, deodorants, pharmaceuticals, medicinal and embalming antiseptic. On account of increasing world population growth, there are notable challenges in nutrient food consumption that stimulates the growing interest in recognition and utilization of different new natural and available food materials. Additionally, the need of natural drug demand for pharmaceutical purposes also encourages scientific community to discover medicinal plants recognized as efficient remedies. Extraction of essential oils from pumpkin seeds stimulates a motivating target because it has valuable pharmacological properties with respect to treat wound healing [9]. These essential oils are involved in international market and most industries. Because of increasing numbers and types of individual oil uses from day to day, researcher including pharmacists, engineers, chemists and physicians were studying about the physical, chemical, and medicinal properties of oils starting at the middle of sixteenth century. Different researchers studied the extraction and characterization of pumpkin seed extracted oil using different extraction methods, but no work has done on the factors that affect the chemical composition of extracted oil. There are a lot of factors that affect the chemical composition of extracted oil. The chemical composition of observed oil is the indication for the purity of the oil yield and can be affected by different extraction process and process parameters. This work focused on Response Surface Methodology (RSM) based optimization and to study the interaction effect of important process parameters (temperature, extraction time and particle size) for maximizing the yield of oil extraction from pumpkin seeds. Additionally, the physico-chemical properties of obtained pumpkin seed oil using optimal process parameters were also investigated.

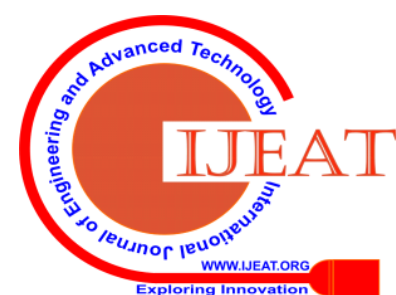




\section{METERIALS AND METHODS}

\section{A. Raw Materials, Apparatus, Chemicals and Reagents}

Pumpkin seeds were obtained from Kose, Shola-Megenagna and Merkato vegitable market center, Addis Ababa, Ethiopia. The seeds were detached from the fruit and washed gently with pure double distilled water to expel other component of pumpkin and impurities. For the experimental studies, following apparatus used were: Rota evaporator, measuring cylinder, burette, conical flasks, standard flasks, round bottom flasks (250 and $500 \mathrm{ml}$ ), pipettes, Screw-capped test tubes, heater, grinding mill, coffee miller, sieve, water bath, magnetic stirrer, separation funnel, Gas chromatography - Mass spectroscopy (GC-MS) (SHIMADZU, GCMS-QP2020-NX),

Fourier Transform-Infrared Ray (FT-IR) (JASCO, FT/IR-4000), digital weighting balance, beakers $(100,250$, and $500 \mathrm{ml}$ ), volumetric flasks (100, 250, and $500 \mathrm{ml})$, vibro-viscometer (SV-10, Switzerland), condenser, Soxhlet apparatus setup, oven, crucibles, centrifuge, refrigerator, and $\mathrm{pH}$ monitors.
Unless specified otherwise, all fine chemicals and media components were obtained from HiMedia Laboratories Private Limited (Addis Ababa, Ethiopia) and Merck (Addis Ababa, Ethiopia), and were of analytical reagent. Water from double distilled unit was utilized for carryout all solution.

\section{B. Preparation of the Plant Materials}

Pumpkin seeds shells were removed manually to get the seeds. They were cleaned and washed for the removal of foreign matter or extraneous impurities such as debris, plant parts, and damaged seeds. They were dried in sun light for a day. The seeds were then weighed accurately to control of oil and cake yield. The shells (seed coat) were often removed from the seed kernel. Then the known weight of sample was taken to investigate the moisture content of the materials. The presence of moisture in the sample was assessed by oven drying at $150{ }^{\circ} \mathrm{C}$ for $3 \mathrm{~h}$ through the potential mass loss of evaporation due to the drying. The shell contained seeds and shell removed seeds samples are presented in the Fig. 1(a) and Fig. (b), respectively.

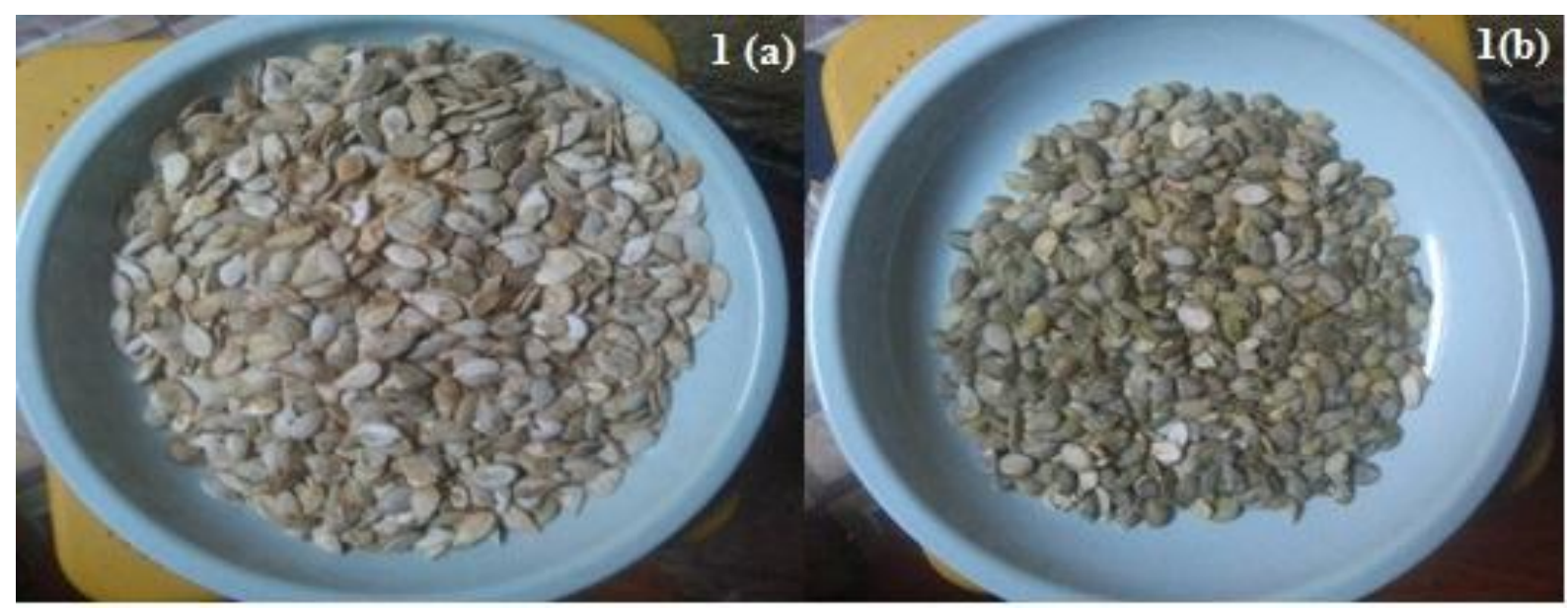

Fig. 1. Pumpkin seeds sample (a) before and (b) after removal of shell

\section{Size Reduction and Sieve Analysis of the Sample}

Laboratory Mortar and pestle was used to crush the seed kernels for reducing the sizes of the dry seeds. In order to increase contact area in terms of volume to surface, they were crushed until the particle size reaches desired point. Further, the powdered sample was subjected to sieve using laboratory ASTM sieves for getting different particle size of the plant materials ranging from $0.25-1.25 \mathrm{~mm}$. The sample powder was stored at $4{ }^{\circ} \mathrm{C}$ for further experiment [10].

\section{Extraction of oil and purification}

Soxhlet procedure was used to extract oils from the pumpkin seeds [11]. About 20g of crushed pumpkin seeds were fed to lab-scale Soxhlet extractor with condenser and $250 \mathrm{ml}$ round bottom flask. Then, $200 \mathrm{ml}$ of the food grade solvent (Ethanol) was added into round bottom distillation flask. The Soxhlet apparatus was then heated up using a heating mantle with temperature controller for controlling the desire value of heating. After heating for the predetermined time, the waded thimble of sample was obtained. The condensed oil was collected into the flask. This extraction process was carried out for predetermined time. The Fig. 2 illustrates the extraction procedure adopted in this work.
After extracting, the flask containing the solvent and lipid was removed through distillation process. To remove the excess solvent, the solvent and extract mixture were placed on water bath. Excess solvent (Ethanol) can be evaporated at $70{ }^{\circ} \mathrm{C}$. Since the oils have low volatility, they retained in the flask [12]. The oil extract mixture was found to be golden yellowish color. Further, this mixture was allowed to settle for $4 \mathrm{~h}$ to collect essential oils as extract and solvent as raffinate. Observed essential oils was separated and kept in refrigerator at $4{ }^{\circ} \mathrm{C}$ for further purification and characterization [13]. The extraction experiments were carried out for the predetermined combinations of process variables with respect to design of experiments.

\section{E. Experimental Design and Analysis}

The optimal condition to get the maximized yield of oils from pumpkin seeds was determined by means of RSM. The considered factors and their respective ranges of the experiments are given in the Table-I.

The optimization of chosen parameters using Box-Behnken design was carried out about 16 numbers of experimental runs with 5 center points.

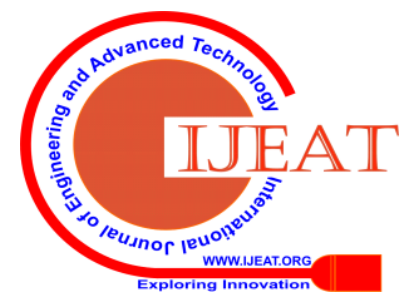


The combinations of selected parameters are given Table-II. The 3-factors, 3-level for all the three factors (temperature, extraction time and particle size) experimental design was used to investigate and validate extraction parameters that affect the extraction yield. Each set of experimental was conducted in duplicate. The software Design-Expert 7.0.0 (Stat-Ease Inc., and Minneapolis, MN, USA) was utilized for design of analysis of data, and to construct a process model. The significance and statistical analysis of developed model was examined for 5\% probability level. The $3 \mathrm{D}$ plots of response surface were developed by fixing one response variable at its optimal point and plotting that against other two variables. The axial points were omitted by making it to Face Centered Quadratic Design. Because of they are out of ranges to which the process parameters were projected to be studied.

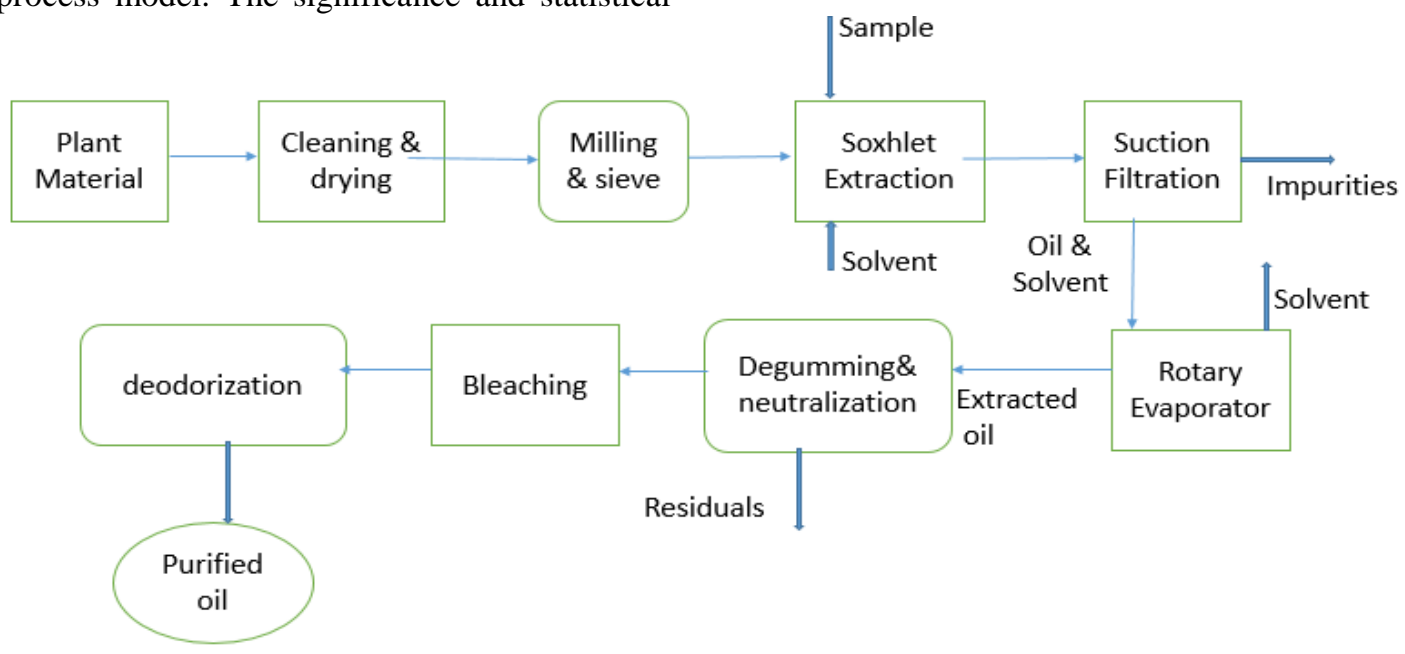

Fig. 2. Process description for extraction and purification of pumpkin seeds oil

Table-I: Factors and respective ranges of the experiments

\begin{tabular}{cccccc}
\hline Factor & Name & Units & Low value & High value \\
\hline A & Temperature & ${ }^{\circ} \mathrm{C}$ & 65 & 85 \\
B & Extraction time & $\min$ & 90 & 270 \\
C & Particle size & $\mathrm{mm}$ & 0.25 & 1.25
\end{tabular}

In the current study, factors considered were: temperature, extraction time and particle size. The main effects of the individual factors and the interaction effect of on the yield of the extracted oils and the optimum value of the parameters were investigated.

Table-II. Combinations of selected parameters for DoE

\begin{tabular}{|c|c|c|c|}
\hline Run & Temperature $\left({ }^{\circ} \mathbf{C}\right)$ & $\begin{array}{c}\text { Extraction time } \\
(\mathbf{m i n})\end{array}$ & $\begin{array}{c}\text { Particle size } \\
(\mathbf{m m})\end{array}$ \\
\hline 1 & 75.00 & 180.00 & 0.75 \\
\hline 2 & 75.00 & 90.00 & 0.25 \\
\hline 3 & 75.00 & 180.00 & 0.75 \\
\hline 4 & 75.00 & 90.00 & 1.25 \\
\hline 5 & 85.00 & 180.00 & 1.25 \\
\hline 6 & 75.00 & 180.00 & 0.75 \\
\hline 7 & 85.00 & 270.00 & 0.75 \\
\hline 8 & 65.00 & 180.00 & 1.25 \\
\hline 9 & 75.00 & 270.00 & 0.25 \\
\hline 10 & 85.00 & 180.00 & 0.25 \\
\hline 11 & 85.00 & 90.00 & 0.75 \\
\hline 12 & 65.00 & 180.00 & 0.25 \\
\hline 13 & 75.00 & 180.00 & 0.75 \\
\hline 14 & 65.00 & 270.00 & 0.75 \\
\hline 15 & 65.00 & 90.00 & 0.75 \\
\hline 16 & 75.00 & 270.00 & 1.25 \\
\hline
\end{tabular}

Using RSM, the factors with three levels for temperature, extraction time and particle size, respectively, replicated two times with a single response of percentage oil yield. There were 16 experimental runs conducted. The obtained results from 16 raw experimental data were fed in the response and made randomized on the design expert software. The ANOVA, the normal residuals plot, predicted vs. actual values, residuals vs. predicted and, the plots of the individual factor and their interactions, the numerical solutions for optimization were studied.

\section{F. Purification of Essential Oils}

The extracted oils obtained as extract contain different impurities that should be removed. So that the extracted oils to be refined for purification for more palatable, stable against rancidity upon storage. The purification process was performed by degumming, neutralization, bleaching and deodorization. The presence of phospholioids creates problems during oil processing and its different applications. Part of these components can be removed by degumming processes. For that, pumpkin seed oils were initially heated to a temperature of $70{ }^{\circ} \mathrm{C}$. Then $2 \%$ (v/v to oil) of citric acid (30\%) was added to the oil. This mixture was subjected to stir for $20 \mathrm{~min}$. Further, the mixture was retained at $80{ }^{\circ} \mathrm{C}$ for 15 min. Then, allowed to cool to room temperature. Then, water (1\%) was added and allowed to settle in holding vessel for 60 min. In order to separate acid degummed oil, the mixture was subjected to centrifuge with $300 \mathrm{rpm}$ for $20 \mathrm{~min}$ [14]. The neutralization process for degummed oil was done by pouring into a beaker followed by heating to $80{ }^{\circ} \mathrm{C}$. $\mathrm{NaOH}$ $(0.1 \mathrm{M})$ was mixed and stirred well to get uniform solution. Followed by $\mathrm{NaCl}$ was added to settle out the soap formation. It was removed by relocated into a clean separating funnel for $1 \mathrm{~h}$. Soap remaining in solution was removed by adding hot water to this solution.

Published By:

Blue Eyes Intelligence Engineering

$\&$ Sciences Publication 
This oil was considered to be neutralized and taken for the further analysis. The soapy wash water was separated by centrifugation and neutral oil was vacuum dried as outlined by Yesim et al., (2011) [5]. The oil was bleached using powdered clay. Bleaching was carried about $20 \mathrm{~min}$ with clay at range of 104 to $116^{\circ} \mathrm{C}$ by applying vacuum (50 mmHg). Consequently, the spent clay was separated by filtration out from the bleached oil [15]. For deodorization, the oil was heated up to $130-160{ }^{\circ} \mathrm{C}$ under a vacuum (2-10 $\mathrm{mmHg}$ ). Though this process, the non-triglyceride components were removed from the oil.

\section{G. Determination of Oil Yield}

The oil yield depends on the processing parameters. The yield of extraction was determined from the relationship of oil extracted and the raw material used for the extraction. The yield of oil (\%) is calculated using (1).

$$
\text { Yield of Oil }(\%)=\frac{\mathrm{m} 1-\mathrm{m} 2}{\mathrm{~m} 1} * 100
$$

Where, $\mathrm{m}_{1}$ denotes the samples weigh before extraction, and $\mathrm{M}_{2}$ denotes the sample weight after extraction which dried in the oven.

\section{H. Determination of Physical Properties of Oils}

Pumpkin seeds were weighted before and after drying in an oven at $150{ }^{\circ} \mathrm{C}$ for $3 \mathrm{~h}$ The percentage moisture in the seed was calculated by adopting AOAC method using (2).

$$
\text { Moisture Present }(\%)=\frac{\mathrm{C} 1-\mathrm{C} 2}{\mathrm{C} 1} * 100 \ldots . \text { (2) }
$$

Where, $\mathrm{C}_{1}=$ original weight of sample, and $\mathrm{C}_{2}=$ weight taken of the sample after drying. Moisture content in the extracted oils determined by heating the oil sample at $105 \pm 1{ }^{\circ} \mathrm{C}$ under the conditions specified by adopting AOAC method. Percentage weight of the moisture was calculated from (xx)

Moisture content in the extracted oil $=\frac{\mathrm{w} 1-\mathrm{w} 2}{\mathrm{w} 1-\mathrm{wo}} * 100$

Where, $\mathrm{w}_{0}=$ weight of empty beaker, $\mathrm{w}_{1}=$ weight of beaker + oil before drying, $w_{2}=$ weight of beaker + oil after drying. The density of the oil was determined through specific gravity calculation using (3).

Specific gravity $(\mathrm{SG})=\frac{\text { (mass of sample in the density bottle) }}{\text { mass of equal volue of water }}$

Kinematic viscosity of the oil was examined using a vibro-viscometer (TA Instruments, ARES-G2). Dynamic viscosity of oil was determined by vibro-viscometer further the kinematic viscometer was calculated using (4).

$$
\text { Kinematic viscosity }(\vartheta)=\frac{\text { dynamic viscosity of oil }}{\text { density of oil }}
$$

Refractive index of the oil was investigated using a refractometer (PCE Intruments-DRB 10). Ash content in the oil was determined by direct incineration of sample using a Muffle Furnace (MF1/02, PCSIR, Pakistan). Determination of crude protein in the oil was estimated by Kjeldhal Apparatus (Model: D-40599, Behr Labor Technik, Gmbh-Germany). Determination of crude fat content was assessed using hexane as a solvent at Soxhlet Method (Model: H-2 1045 Extraction Unit, Hoganas, Sweden). Crude fiber was determined in fat removed samples by reacting with $1.25 \% \mathrm{H}_{2} \mathrm{SO}_{4}$ followed by treatment with $1.25 \% \mathrm{NaOH}$ solutions. Crude fiber of the samples was determined Labconco Fibertech, (Labconco Corporation Kansas, USA).
Carbohydrate was calculated according to the following relation:

Carbohydrate $\%=100-($ Moisture contents $\%+$ crude protein $\%+$ crude fat $\%+$ crude fiber $\%+$ ash $\%$ ).

\section{Determination of Chemical Properties of Oils}

To determine the acid value of the extracted oil, oil sample (5g) was taken in 250ml flask. The sample was dissolved in alcohol (mixture of 25ml-diethyl ether and 25ml-ethanol). Followed by 2-3 drops of phenolphthalein was added. The free acid was titrated against standard $\mathrm{KOH}(0.1 \mathrm{~N})$ solution at a uniform rate of $30 \mathrm{drops} / \mathrm{min}$. The end point was considered to be the red coloration that did not fade within 10 seconds. The acid value was estimated using (5).

$$
\text { Acid value }=\frac{\mathrm{v} * c * 56.1}{\mathrm{wo}}
$$

Where, $\mathrm{c}=$ concentration of $\mathrm{KOH}, 56.1$ = equivalent weight of $\mathrm{KOH}, \mathrm{v}=$ volume of $\mathrm{KOH}, \mathrm{w}_{\mathrm{o}}=$ weight of oil.

Saponification, peroxide, and iodine values of the extracted oil were determined by following AOAC method.

\section{RESULTS AND DISCUSSION}

\section{A. Soxhlet Extraction According to DoE}

Owing to optimize the process, the following parameters were considered: extraction time, extraction temperature, and particle size. Soxhlet setup was used for extraction of pumpkin seeds oils. Using the combinations of chosen parameters, as provided in Table-III, experiments were carried out. The obtained yield of oil (\%) was determined by duplicated experiments and mean value with standard deviations are presented in the table as results.

Table III. Average yield of pumpkin seeds oil extract

\begin{tabular}{|c|c|}
\hline Run & Average oil yield (\%) \\
\hline 1 & $52.2 \pm 2.74$ \\
\hline 2 & $36.62 \pm 0.8$ \\
\hline 3 & $52.7 \pm 2.86$ \\
\hline 4 & $38.4 \pm 0.85$ \\
\hline 5 & $49.8 \pm 2.43$ \\
\hline 6 & $52.5 \pm 2.97$ \\
\hline 7 & $53.2 \pm 3.06$ \\
\hline 8 & $46.93 \pm 1.12$ \\
\hline 9 & $56.2 \pm 3.88$ \\
\hline 10 & $47.87 \pm 2.23$ \\
\hline 11 & $37.16 \pm 0.81$ \\
\hline 12 & $46.7 \pm 1.84$ \\
\hline 13 & $52.56 \pm 2.62$ \\
\hline 14 & $44.02 \pm 1.66$ \\
\hline 15 & $35.78 \pm 0.71$ \\
\hline 16 & $48.75 \pm 2.80$ \\
\hline
\end{tabular}

\section{B. Polynomial Model for Extraction}

\section{- Statistical Analysis and Model Selection}

Model selection is key point that needs for modeling, analyzing the statistical significance of terms and optimization for maximizing the oil yield. There were five common types of model equation can be fitted as model of response of the variables by Design expert software. The Table-IV shows the observed values of mean square, sum of squares, adjusted R-square, R-square (predicted), p-value, F-value, lack of fitness, and significance for different models when the oil yield (response) is evaluated based on ANOVA analysis. 
From the analysis result, it cleared that the quadratic model has greater value of significance model and F-value. Also, lack of fitness indicated as non-significance. Thus, the quadratic model can be considered to describe its correlation with the independent factors. The quadratic model showed a significance of $\mathrm{F}$ - value was predicted at $95 \%$ confidence interval. Also, the F-value of 45.70 suggests the model is quite significant than other models. The process modeling in terms of quadratic model is presented in (6).

\section{- Analysis of the Variance of the Model}

The Table-V shows analysis of variance (ANOVA) obtained which explains the significance of different factors. The revealed that the hypotheses had no main effect on factor $A$, no main effect on $B$, no main effect for factor $C$, no $A B$ interaction effect, no $\mathrm{AC}$ interaction effect and no $\mathrm{BC}$ interaction effect on the yield of oils. The Table-V shows the analysis of variance for the data using $\alpha=0.05$.

It was found that there are many insignificant model terms (that may not counting those required to support hierarchy), In this study A, B, C, D, BC, $\mathrm{A}^{2}, \mathrm{~B}^{2}, \mathrm{C}^{2}$ were very significant model terms and $\mathrm{AB}$ were significant model terms. $\mathrm{AC}$ had $\mathrm{P}$-Values greater than 0.1. That indicated the model terms was not significant correlation. The non-significant obseveation of "Lack of Fit F-value" (1.05) suggests the lack of fit was relative to the pure error. It was observd that there is a $5.053 \%$ chance of "Lack of Fit F-value" that could occur due to noise. Thus, the model holds good for fit.

\section{Diagnostic Tests for Response}

After analysing ANOVA, the predited model should be diagnosed for statistical properties. There are different techniques can be used for diagnostic details test. The widely used diagnostic is the plot of normal probability vs residuals, and predicted vs actual, the same is given in Fig. 3. The data points were observed to be fixed at linear. All the entire response data were good line up on the linear line.

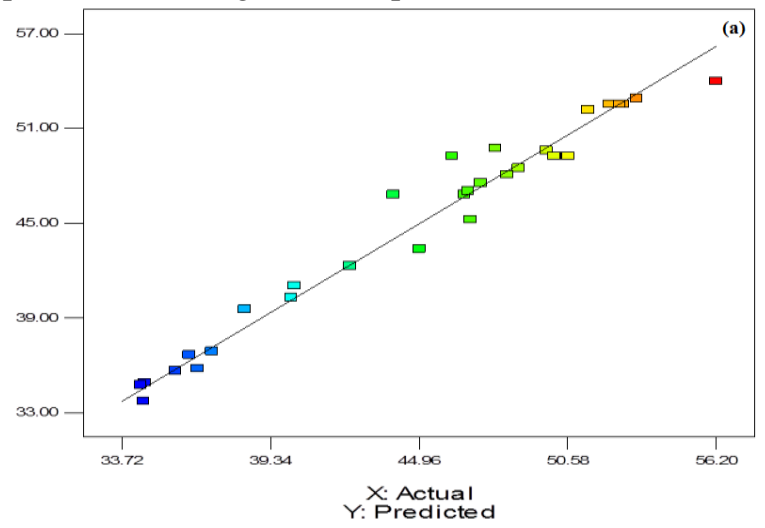

Fig. 3. Plot for predicted values versus actual values

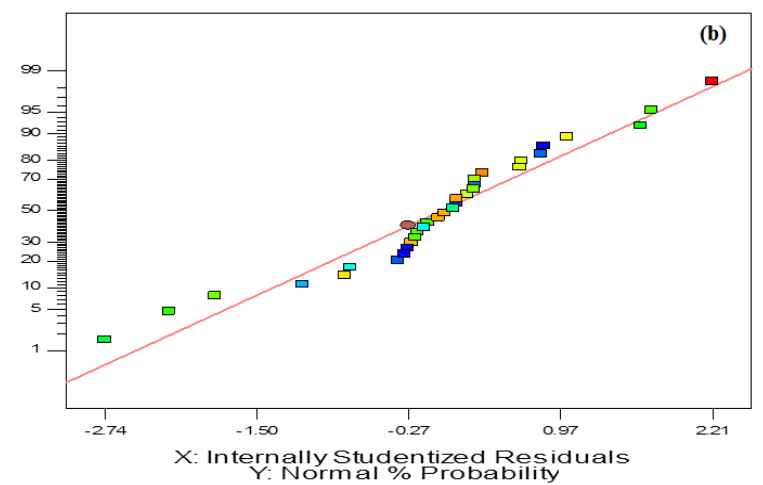

Fig. 4. Normal probability plot of the studentized residuals

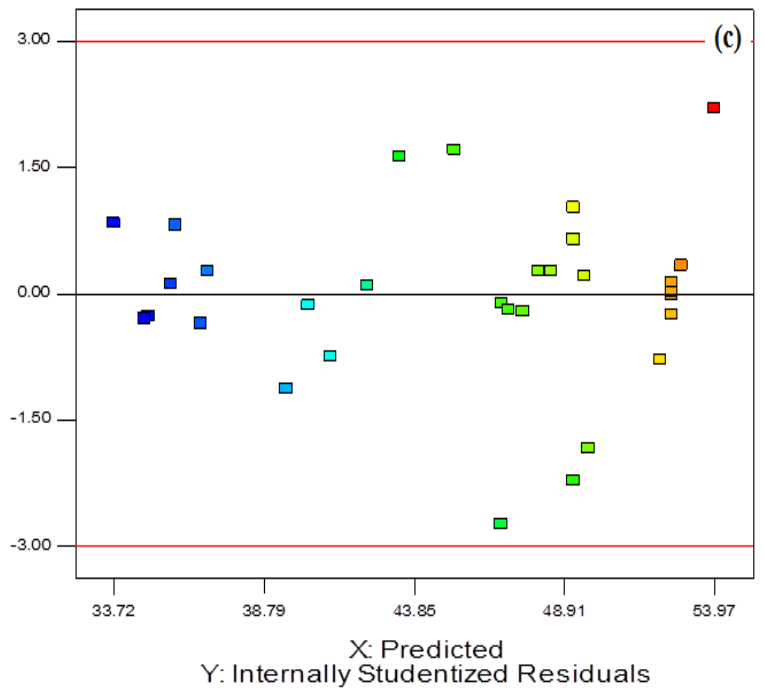

Fig. 5. Residual value versus predicated value of percentage oil yield

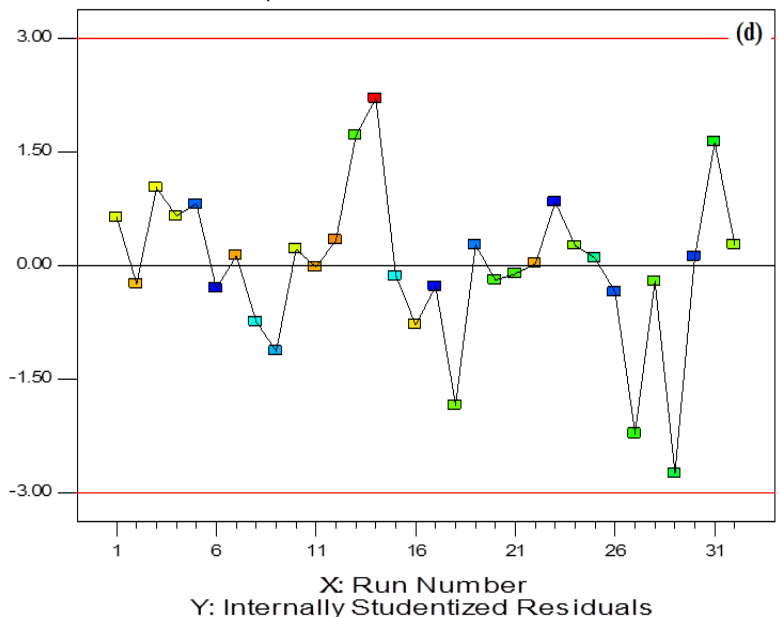

Fig. 6. Residuals value versus run

Additionally, the relation between actual values and predicted values illustrated that the actual values are distributed relatively close to the straight line. That indicated the model had good fitness. The normal distribution of the error term (residuals) and the residuals verses predicted value of the model data is presented in Fig. 4. Unless the model should not satisfy this criteria it is not advisable to use the model for different purpose. The plot of residuals verses predicted value (Fig. 5) showed that the residuals did not follow any pattern that means no serious deviation found on the assumptions.
Published By:

Blue Eyes Intelligence Engineering

\& Sciences Publication

(C) Copyright: All rights reserved. 
Extraction of Essential Oils from Pumpkin Seeds: RSM Based Process Modeling, Optimization and Oil Characterization

Table-IV. Summary statistics of the models

\begin{tabular}{|c|c|c|c|c|c|c|c|}
\hline Model & $\begin{array}{c}\text { Sum of } \\
\text { square }\end{array}$ & Mean square & F-value & $\begin{array}{c}\text { Adj } \\
\text { R-squared }\end{array}$ & $\begin{array}{c}\text { Pred } \\
\text { R-square }\end{array}$ & $\begin{array}{c}\text { Significance } \\
\text { of model }\end{array}$ & $\begin{array}{c}\text { Significance } \\
\text { lack of fitness }\end{array}$ \\
\hline Mean & 0.000 & - & - & 0.000 & -0.0656 & - & Significant \\
\hline Linear & 762.69 & 190.67 & 9.09 & 0.5108 & 0.4284 & Significant & Significant \\
\hline 2FI & 862.80 & 86.28 & 3.89 & 0.4822 & 0.2876 & Significant & Significant \\
\hline Quadratic & 1289.86 & 99.22 & 45.70 & 0.9819 & 0.9494 & Significant & Not-Significant \\
\hline Cubic & 1304.93 & 59.32 & 22.23 & 0.9378 & 0.4340 & Significant & Not-Significant \\
\hline
\end{tabular}

The randomness of the plot implies that the model is adequate and there is no indication of a severe problem. Therefore, the model equation can fit to design the model. The plot of residuals versus run plot is given in Fig. 6. The points were connected with one another and ffamed as visible pattern.

It showed about the testing of accuracy of oil yield that was modeled through quadratic model. The plot of studentized residuals vs run was carried out. In this study, the residuals were scattered randomly with clear visible pattern around \pm 3.00 . This was a good indication of good fitness of the model observed from the experimental data.

Table-V. Data from analysis of variance

\begin{tabular}{|c|c|c|c|c|c|c|}
\hline Source & Sum of Squares & df & Mean Square & F Value & $\begin{array}{l}\text { p-Value } \\
\text { Pron }>\text { F }\end{array}$ & \\
\hline Model & 1289.86 & 13 & 99.22 & 45.70 & $<0.0001$ & Significant \\
\hline $\mathrm{A}$ & 24.03 & 1 & 24.03 & 11.07 & 0.0037 & \\
\hline $\mathrm{C}$ & 54.61 & 1 & 54.61 & 25.16 & $<0.0001$ & \\
\hline $\mathrm{AB}$ & 11.74 & 1 & 11.74 & 5.41 & 0.0320 & \\
\hline AC & 1.07 & 1 & 1.07 & 0.49 & 0.4925 & \\
\hline $\mathrm{BC}$ & 42.69 & 1 & 42.69 & 19.66 & 0.0003 & \\
\hline $\mathrm{A}^{2}$ & 74.30 & 1 & 74.30 & 34.22 & $<0.0001$ & \\
\hline $\mathrm{B}^{2}$ & 331.02 & 1 & 331.02 & 152.47 & $<0.0001$ & \\
\hline $\mathrm{C}^{2}$ & 21.75 & 1 & 21.75 & 10.02 & 0.0054 & \\
\hline Residual & 39.08 & 18 & 2.17 & & & \\
\hline Lack of Fit & 26.47 & 12 & 2.21 & 1.05 & 0.5053 & Not significant \\
\hline Pure Error & 12.61 & 6 & 2.10 & & & \\
\hline Cor Total & 1328.94 & 31 & & & & \\
\hline
\end{tabular}

$\mathrm{A}=$ Temperature, $\mathrm{B}=$ Extraction time, $\mathrm{C}=$ Particle size

$-159.572+(4.456 \times$ Temperature $)+(0.298 \times$

Extraction time $)+(12.78000 \times$ Particle size $\times$ 1.34583E $-003 \times$ Temperature $\times$ Extraction time $)+$ $(0.073000 \times$ Temperature $\times$ Particle size $-0.0513 \times$ Extraction time $\times$ Particlesie) $-0.0304 \times$

Temperature $^{2}-7.9413 \mathrm{E}-004 \times$ Extractiontime $^{2}-$ $6.595 \times$ Particle size ${ }^{2}$

\section{Interaction Effect of Process Variables and} Optimization

Fig.7 shows the effect of the independent variables, temperature and time on oil yield. From the observations, the yield of pumpkin seeds oil increases at various temperature and extraction time interactions. The close observations about the relationship revealed that increase in temperature resulted in increase of the oil yield. The yield was more while comparing to yield increases with respect extraction time. From these observations, it was cleared that the more steepness of the relation between temperature and oil yield than extraction time. The interaction effect of independent parameters, temperature and particle size on the oil yield is presented Fig. 8. It showed the increased oil yield for an increase with temperature but decreases the particle size. In all combination increasing temperature up to maximum point followed by more steepness to the yield along with increasing the extraction time with a decreasing the particle size. This study shows that maintaining temperature under considerable amount will affect the amount of oil production significantly. Thus, temperature should be taken as special attention on oil extraction. As per the understandings from al combination of variables, increasing extraction time and the temperature had a positively correlation with the oil yield but the particle size showed negatively correlated. The same kind of effect was observes while studying the interaction between particle size and extraction time on the oil yield (Fig. 9). It showed that the positive correction with time nevertheless, negative correlation with particle size. The increasing temperature up to optimum point could help to achieve the maximum extraction oil yield. The optimum temperature enhances the solubility of the extraction compounds. From the 3D surface graphs, the oil yield was found to be enhanced with increasing temperature. The use of higher temperatures supports to break the molecules of the sample that results the higher oil yield. 

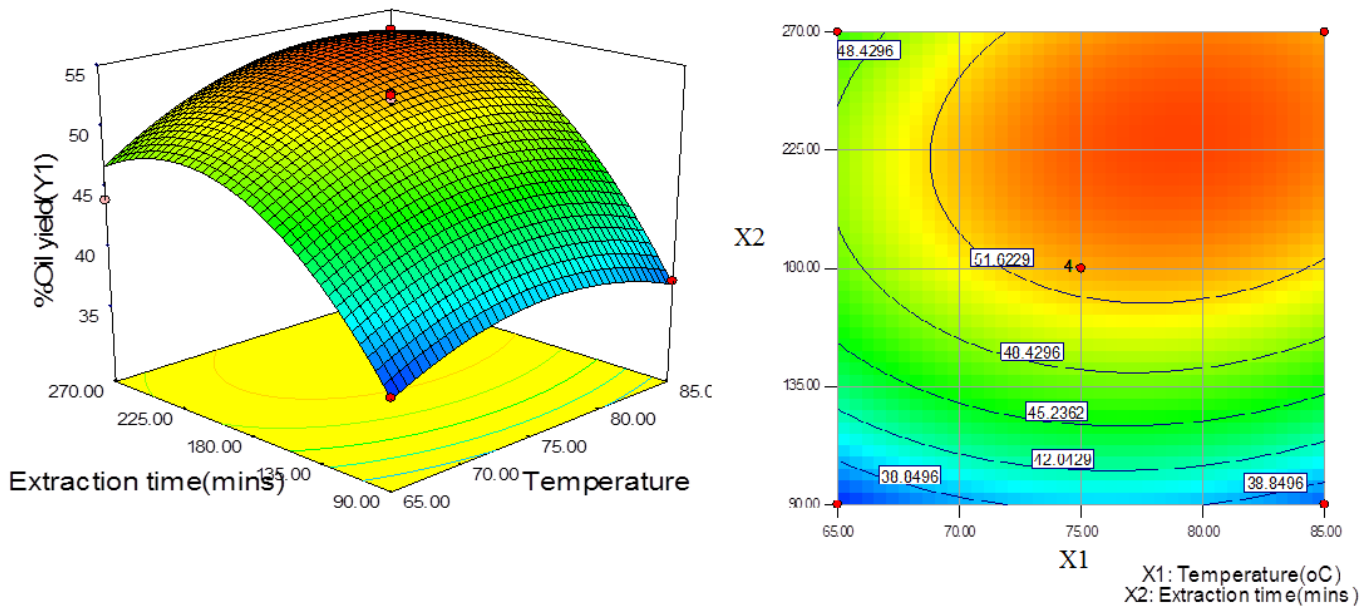

Fig. 7. Interaction effect of time and temperature on oil yield, (a) Response surface (b) Contour plots
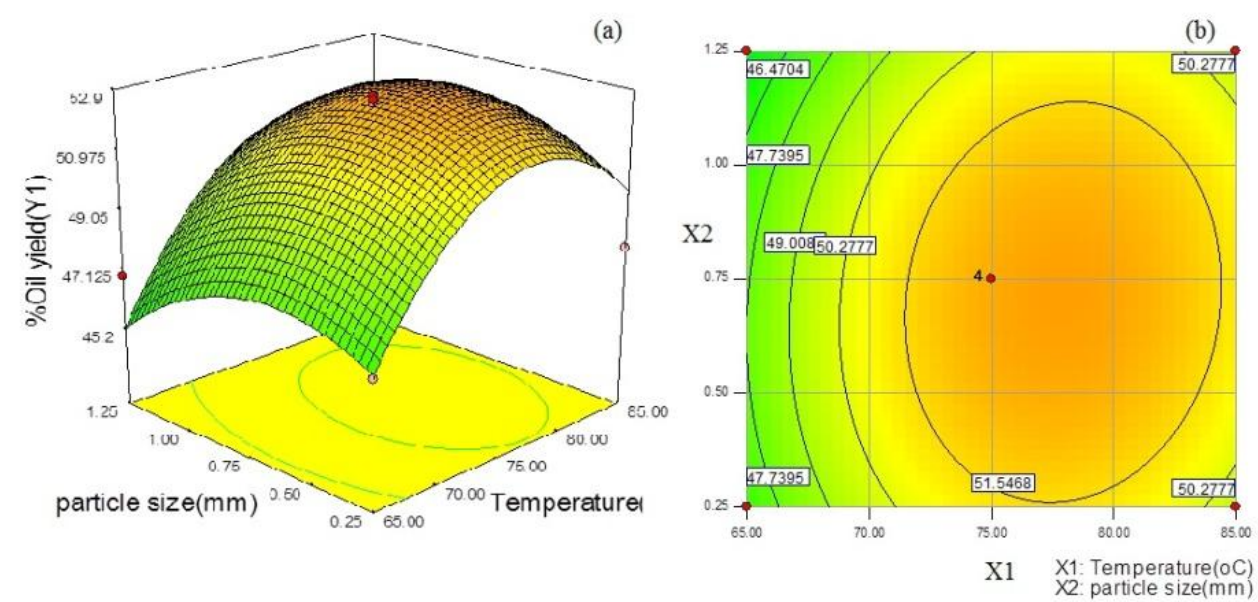

Fig. 8. Interaction effect of particle size and temperature on oil yield, (a) Response surface (b) Contour plots
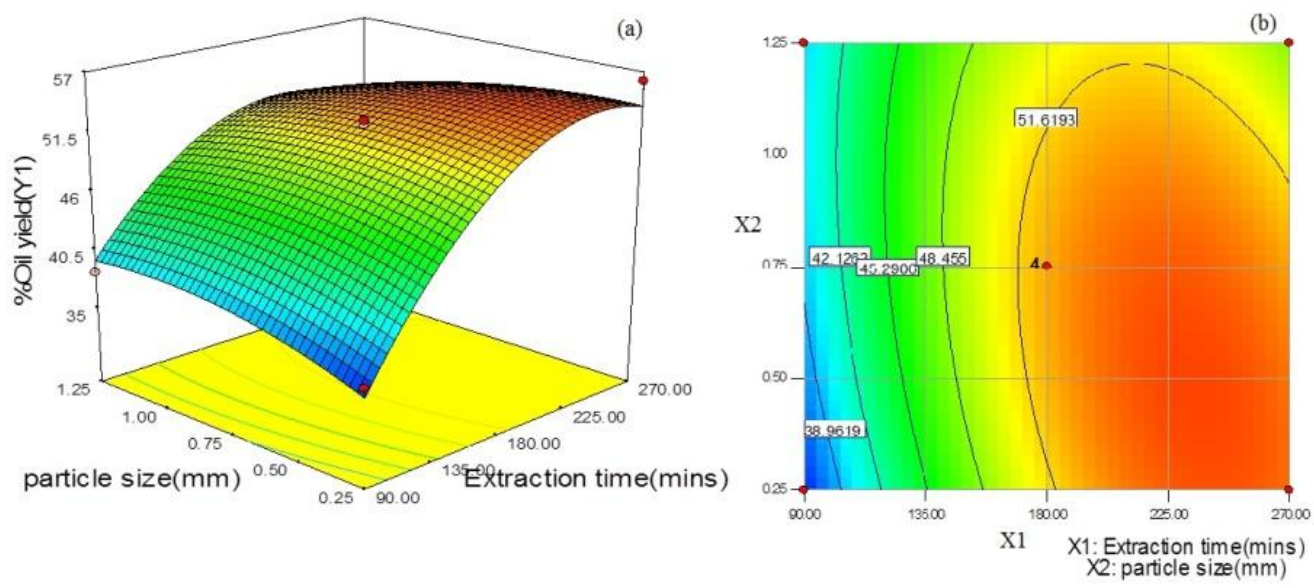

Fig. 9. Interaction effect of particle size and time on oil yield, (a) Response surface (b) Contour plots

Owing to get the maximum yield, the optimization of selected parameters was targeted. The point optimization technique was used for all chosen independent variables. Under the working conditions, all the responses and factors (extraction temperature, particle size, and time) were employed for the optimization analysis. Optimization was targeted to maximize the yield of pumpkin seed oil when the values of independent factors were taken in the range studied.

To determine the optimum conditions, the process should operate at values of high composite of desirability that provides the maximum response. The factors with suitable value of combination satisfy the ultimate goals of response. In this study, combination of

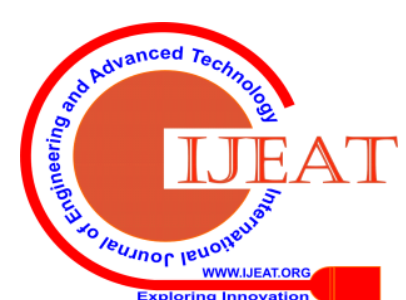


each of the factor gave the highest composite desirability (0.957). The experimental values and corresponding predicted values for the yield under the optimum conditions are presented in Table-VI.

Table-VI. The acquired optimal values

\begin{tabular}{|c|c|}
\hline Variables & Optimum results \\
\hline Temperature $\left({ }^{\circ} \mathrm{C}\right)$ & 75 \\
\hline Extraction time (min) & 270 \\
\hline Particle size (mm) & 0.25 \\
\hline Experimental percentage of the oil yield (\%) & 56.20 \\
\hline Deviation in percent & 0.33 \\
\hline
\end{tabular}

The model predicted that $55.87 \%$ oil yield at extraction temperature of $75{ }^{\circ} \mathrm{C}$, extraction time of $270 \mathrm{~min}$, and particle size of $0.25 \mathrm{~mm}$. The experimental value obtained at this condition was observed to be $56.20 \%$. This value revealed the close agreement with predicted result from the model and validated experimental findings under optimal condition.

\section{E. Physico-Chemical Properties of Extracted Oils}

The result obtained indicated that the oil was of high quality. Sample of oil obtained from pumpkin seeds by solvent extraction were subjected to various physical \& chemical characterizations (Table-VII and Table- VIII). Mean values for physical parameters of extracted oil including moisture content of oil, specific gravity, $\mathrm{pH}$ and kinematic viscosity $\left(\mathrm{m}^{2} / \mathrm{s}\right)$ were: $0.91,0.9109,4.23$ and 34.9 , respectively. The mean value for chemical properties, iodine value, free fatty acid value, acid value and saponification value were found to be $97.8 \pm 0.4 \mathrm{I}_{2} \mathrm{~g} / 100 \mathrm{~g}$ oil, $0.356 \pm 0.023$, $0.713 \pm 0.07 \mathrm{mg} \mathrm{KOH} / \mathrm{g}$ oil and $175.8 \pm 3.71 \mathrm{mg} \mathrm{KOH} / \mathrm{g}$ oil, respectively its clears he non-significant difference with literature reports $[16,17,18]$.

\section{F. FT-IR Analysis}

The presence of functional groups in the pumpkin seeds oil (obtained from optimal condition) was determined by FT-IR spectrum analysis. Fig. 10 shows \% Transmittance versus wave length $\left(\mathrm{cm}^{-1}\right)$ graph of FT-IR analysis. Each peak represents specific functional group present in the pumpkin seeds oil. The oil composition affects the exact position of the band and yields shifts when the proportion of the fatty acid changes. The pumpkin seed oil spectra showed a peak at $3462.72 \mathrm{~cm}^{-1}$ for $\mathrm{N}-\mathrm{H}$, sharp peak at $3004 \mathrm{~cm}^{-1}$ for $\mathrm{C}-\mathrm{H}$ stretching vibration of the cis-double bond $(=\mathrm{C}-\mathrm{H})$, sharp peaks at $2982.5 \mathrm{~cm}^{-1}$ for symmetric and asymmetric stretching vibration of the alkanes, $\mathrm{C}-\mathrm{H}$ stretching is found to be aldehydes and acids presence due to the appearance of absorption peak at $2843 \mathrm{~cm}^{-1}$, O-H stretching indicates carboxylic acid the band at $2127.9 \mathrm{~cm}^{-1}$ representing alkynes indicates $\mathrm{C} \equiv \mathrm{C}$ stretching, a sharp peak at $1752.39 \mathrm{~cm}^{-1}$ for ester carbonyl functional group of the triglycerides $(\mathrm{C}=\mathrm{O})$ and from 1700-1600 $\mathrm{cm}^{-1}$ asymmetric carboxyl stretching and the peak is $1645.69 \mathrm{~cm}^{-1}$ indicate $\mathrm{C}-\mathrm{N}$ aliphatic amine free carboxyl group compound. The peaks below 1009.57 $\mathrm{cm}^{-1}$ represent the fingerprint regions. $1167.57 \mathrm{~cm}^{-1}$ represent stretching vibration of the $\mathrm{C}-\mathrm{O}$ alkynes, 739.74 $\mathrm{cm}^{-1}$ represents overlapping of the $\mathrm{CH}_{2}$ rocking vibration and the out-of-plane vibration of cis-disubstituted olefins. The characteristic functional groups in the oil sample were examined. As well known, they are the responsible for activities and behaviors which exhibit their therapeutic and pharmaceutical applications [19].

\section{G. GC-MS Analysis of Extracted Oils}

The composition of fatty acids in the pumpkin seeds oil was evaluated for its stability and nutritional quality. Therefore, pumpkin seeds oil obtained at optimal condition subjected to Gas Chromatography-Mass Spectroscopy Analysis (Spectrum given in Fig. 11). From the observations, a higher value of oil unsaturation provides the more susceptible property to oxidative deterioration. In contrast, there are significant data to recommend a reduction in monounsaturated and a moderate increase in saturated and n-3 and n-6 polyunsaturated fatty acids for nutrition. They can be prevented coronary heart diseases. These fatty acids composition varies depending on different parameters including growing area, variety, climate and ripeness. The fatty acid composition is a major determinant of quality of the oil. GC-MS results showed the fatty acid composition of crude pumpkin seeds oils composed with 2,6-Octadien-1-ol, 3,7-dimethyl-, (Z)-; 1H-Cyclopenta[c] furan-3 (3aH) -one,6, 6a-dihydro-1- (1,3-dioxolan-2-yl)-, (3aR,1trans,6a-cis); heptane, 2,2-dimethyl-3-methylene-, $\quad$ (1S)-; 3,3-Dimethyl-4-methylamino-butan-2-one; Hydrazine, 1-(5-hexenyl)-1-methyl-; 2-(Prop-2-enoyloxy) pentadecane; 2-Propenoic acid, 1-methylundecyl ester; 9,12octadecadienoic acid (Z,Z) Bicyclo[10.1.0] tridec-1-ene; 11(2-Cyclopenten-1-yl) undecanoic acid. The fatty acid composition of refined pumpkin seeds oil included: 2-(4-Fluoro-1H-imidazol-5-yl) ethylamine; 11-(2-Cyclopenten-1-yl) undecanoic acid, (+)-; 2-(4-Fluoro-1H-imidazol-5-y) ethylamine; pentadecanoic acid, methyl ester; 1-Octadecanamine, N-methyl-; 9,12octadecadienoic acid, ethyl ester; heptane 6,6-dimethyl-2-methylene, 2-Octenal, (E)-; Heptadecanoic acid ethyl ester; 2,4,6-Trimethyl-1,6-heptadien-4-ol; dl-3,7-Dimethyl-3-hydroxy-1,6-octadiene;

9-octadecadienoic acid, methyl ester(E); 2-Propenoic acid, 1-methylundecyl

5-Cyclopropylcarbonyloxypentadecane;

3,7-Dimethyl-octa-1,6-dien-3-ol. 


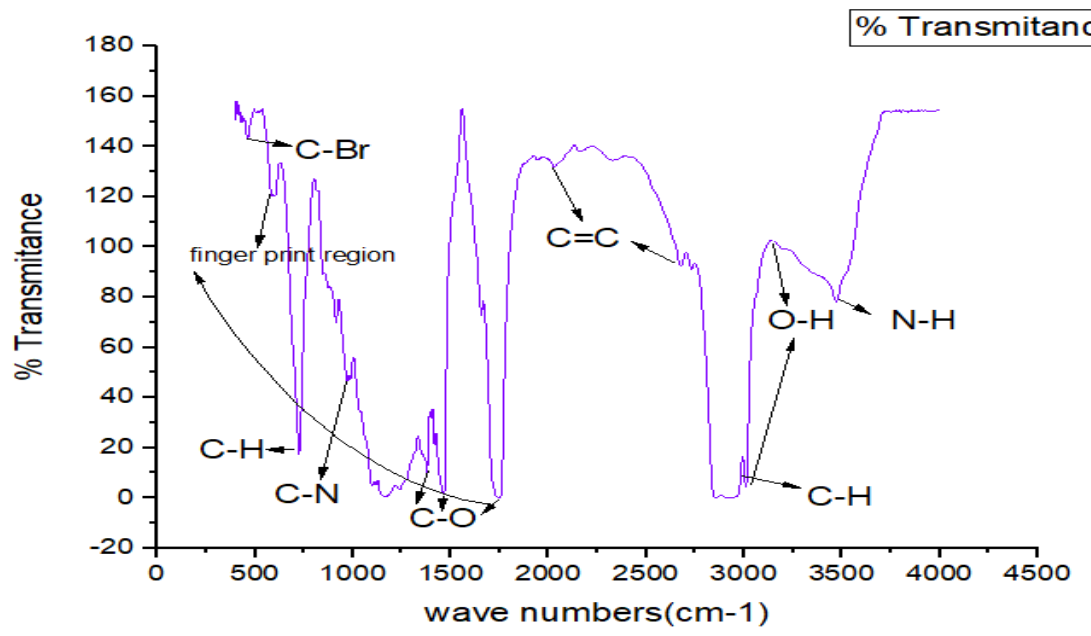

Fig. 10. FT-IR spectrum of extracted oils sample
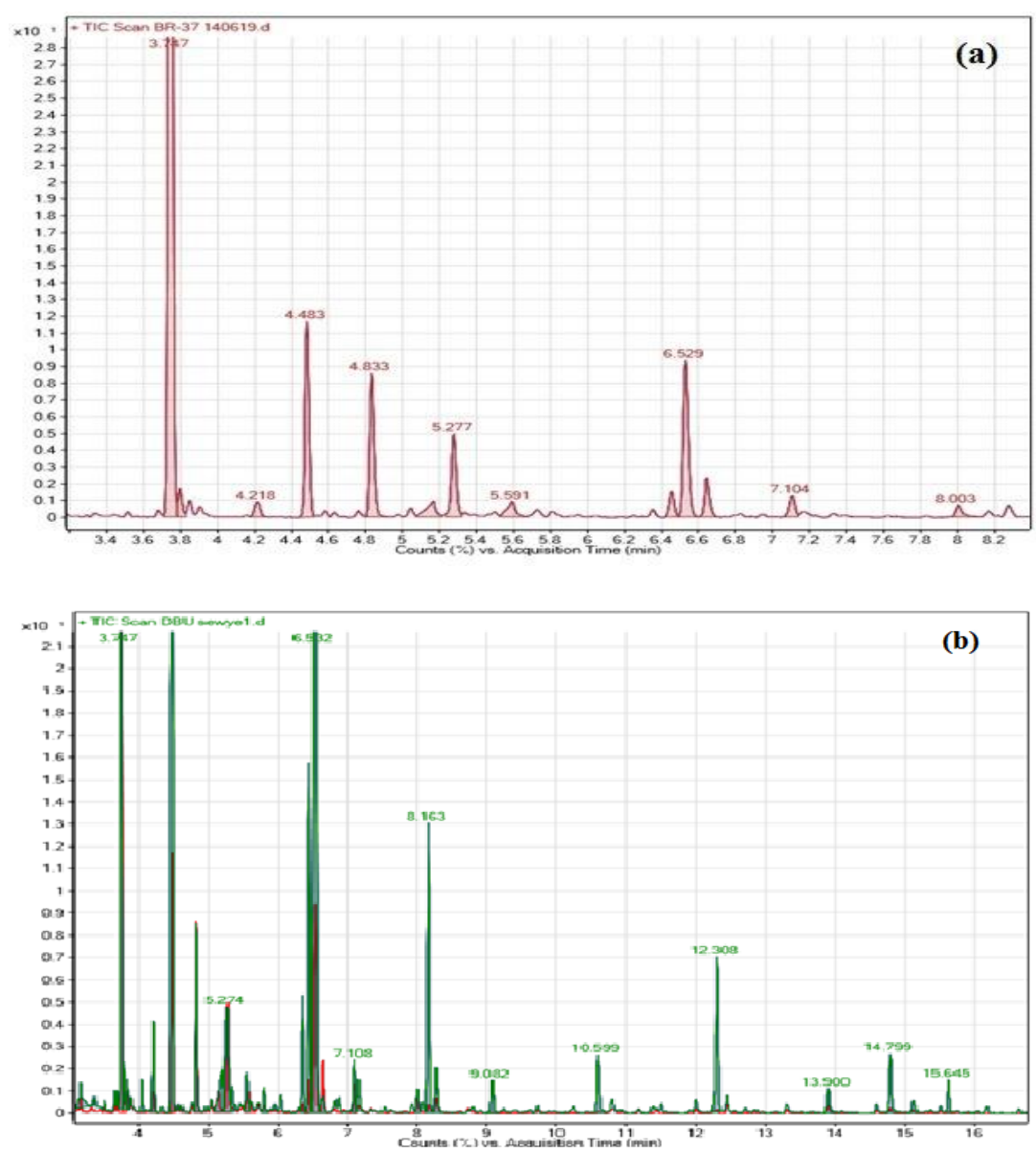

Fig. 11. GC-MS spectra results for extracted crude (a) and refined (b) oil

From the analysis results the saturated fatty acids (SFA) were found to be: Myristic acid (C14:0), Palmitic acid (C16:0) and Steric acid (C18:0), the monounsaturated fatty acids (MUFA) include Oleic acid (C18:1) while the polyunsaturated fatty acid (PUFA) include Linoleic acid (C18:2) and Eicosenoic acid (C20:1) were found in the pumpkin seeds oil. They consisted more than $90 \%$ of the total oil obtained. This profile was reported by several investigators [20,21]. GLC analysis of oil showed that the oil contained highest amount of oleic acid (40.58\%). It was observed that stearic acid, palmatic acid and linoleic acid contents were found to be $27.06 \%, 17.39 \%$ and $14.97 \%$, respectively [22].The seed oil contained $21.5 \%$ and $26.2 \%$ saturated fatty acids for crude oil and refined oil respectively, with the major one being mystric acid (1.83-3.61\%); palmitic acid (5.6\%-15.4\%) and stearic acid (3.85\%-12.38\%), while it was high in unsaturated fatty acids with a total content of $72.3 \%$, and $64.57 \%$. The unsaturated fatty acids content of was similar to that of the other studies on pumpkin seed in Cucurbitaceae species [23].

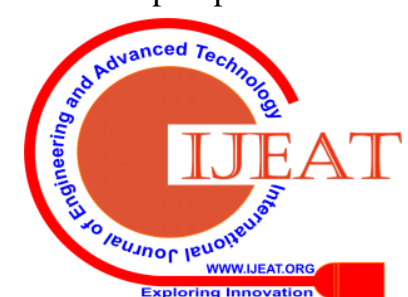


Extraction of Essential Oils from Pumpkin Seeds: RSM Based Process Modeling, Optimization and Oil Characterization

Table-VII. Physical property of pumpkin seeds crude and refined oil

\begin{tabular}{|c|c|c|}
\hline \multirow{2}{*}{ Physical parameter } & \multicolumn{2}{|c|}{ Value } \\
\cline { 2 - 3 } & Crude & Refined \\
\hline Color & Dark-brown & 0.9103 \\
\hline Specific gravity $\left(\mathrm{g} / \mathrm{cm}^{3}\right)$ & 0.9109 & 5.81 \\
\hline $\mathrm{pH}$ & 4.23 & 34.67 \\
\hline Kinematic viscosity $\left(\mathrm{m}^{2} / \mathrm{s}\right)$ & 35.13 & 910.3 \\
\hline Density $\left(\mathrm{kg} / \mathrm{m}^{3}\right)$ & 910.9 & 0.73 \\
\hline Moisture content of oil $(\%)$ & 1.09 & 1.37 \\
\hline Refractive index $\left(\right.$ at $\left.40^{\circ} \mathrm{C}\right)$ & 1.53 & \\
\hline
\end{tabular}

Table-VIII. Chemical properties of pumpkin seeds oil

\begin{tabular}{|c|c|c|}
\hline \multirow{2}{*}{ Chemical parameter } & \multicolumn{2}{|c|}{ Value } \\
\cline { 2 - 3 } & Crude & Refined \\
\cline { 2 - 3 } & $0.59 \pm 0.07$ & $0.123 \pm 0.006$ \\
\hline Free fatty Acids & $1.18 \pm 0.14$ & $0.246 \pm 0.013$ \\
\hline Acid Value (mg KOH/g) & $174.3 \pm 4.28$ & $176.6 \pm 3.72$ \\
\hline Saponification value (mg KOH/g) & $3.22 \pm 0.14$ & $0.91 \pm 0.08$ \\
\hline Peroxide value (meq. $\mathrm{O}_{2} / \mathrm{Kg}$ Oil) & $98.36 \pm 0.51$ & $96.84 \pm 0.39$ \\
\hline Iodine Value (I g/100 g Oil) & $0.59 \pm 0.07$ & $0.123 \pm 0.006$ \\
\hline
\end{tabular}

The unsaturated fatty acids, oleic acid and linoleic acid in the crude and refined oil were found to be $37.64 \& 26.93 \%$ and $40.6 \& 31.7 \%$, respectively. In most other studies on the fatty acid composition of C. pepo, the percent of linoleic acid was quite higher (43.1-55.6\%) than that of oleic acid (20.4-37.8\%). Nevertheless, the percentages of linoleic and oleic acids for crude and refined oil were observed to be nearly the same (40.6 \& $31.7 \%$ and 37.64 \& 26.93\%, respectively). High degree of unsaturation has made it a suitable for use as valuable drying agent. The lower free fatty acid content showed the suitability of the oil for probably edible purpose. Also, the level of other fatty acids in the oil was low. That coincides with different reports reported else ever [24-26]. This results were in agreement with other studies which, observed that, linoleic acid was the principal fatty acid followed by oleic acid in pumpkin seed oil. The amount of linoleic acid present in seeds oil is high, so, it suggests that the pumpkin seed oil is highly nutritious. The polyunsaturated fatty acids (PUFAs) have an impact on human health in the prevention of cardiovascular diseases, coronary heart diseases and cancer. Additionally, thrombotic, inflammatory, and autoimmune disease; diabetes type two, renal diseases; hypertension; and rheumatoid arthritis, ulcerative colitis, and Crohn's diseases can also be prevented.

\section{CONCLUSION}

This study aimed to optimize the extraction of essential oils from pumpkin seeds. The extraction was carried out using Soxhlet extractor. Ethanol was used as a solvent, and the processing parameters, namely, temperature, extraction time and particle size were chosen as the main factors to be optimized. RSM method was used to develop a model for processing of extraction and optimize the parameters whereas to archive the maximum yield of oils. The experimental results obtained through Box-Behnken design were fitted with the analysis. As per the predictions, the maximum yield is 56.2 percent by mass was found at extraction temperature of $75^{\circ} \mathrm{C}$, extraction time of $270 \mathrm{~min}$ and solid particle size of $0.25 \mathrm{~mm}$. The quadratic model of polynomial process equation was developed. The ANOVA analysis on the modeling confirmed that the extraction temperature, extraction time and particle size are showing a significant effect on the oil yield. In addition, using optimal condition, essential oils were extracted then purified further they were subjected to analysis for physical and chemical properties. The functional groups were analyzed through FT-IR. The chemical compositions of extracted oils were identified using GC-MS. The major constituents of the observed oils were possessed with ketones, alkenes. This kind of vegetable oil can be a quality and stability contained products which promise a consumer acceptance and sales.

\section{ACKNOWLEDGMENT}

This research was supported by, Chemical Engineering Dept., Addis Ababa Science and Technology University, Ethiopia.

\section{REFERENCES}

1. A. Abbas, A. Nargis, N. H. Othman, A. F. Noor, G. Sadik, J. Hossen, "Oxidation Stability and Compositional Characteristics of Oils from Microwave Roasted Pumpkin Seeds during Thermal Oxidation" International Journal of Food Properties., vol. 20 (11), 2017, pp 2569-80. https://doi.org/10.1080/10942912.2016.1244544.

2. G. Neelamma, B. D. Swamy, P. Dhamodaran, "Phytochemical and Pharmacological overview of Cucurbita Maxima and Future Perspective as Potential Phytotherapeutic Agent", European Journal of Pharmaceutical and Medical Research., vol. 3 (8), 2016, pp. 277-87.

3. J. Xiaofei, M. Chang, X. Wang, Q. Jin, X. Wang, "Ultrasonics Sonochemistry the Effect of Ultrasound on Enzymatic Degumming Process of Rapeseed Oil by the use of Phospholipase", Ultrasonics Sonochemistry, vol. 21 (1), 2014, Pp.142-48. https://doi.org/10 .1016/j.ultsonch.2013.07.018.

4. K. Atif, "Bleaching of Vegetable Oil Using Organic Acid Activated Fuller's Earth (Bentonite Clay)" Global Journal of Researches in Engineering: Chemical Engineering, vil. 15 (2), 2015, pp. 1-6.

5. P. Alessandro, P. Angelini, G. Bertuzzi, R. Venanzoni, "Some Biological Activities of Essential Oils" Medicinal \& Aromatic Plants, vol. 2 (5), 2013, pp. 2-5. https://doi.org/10.4172/2167-0412.1000136

6. S. Intan, C. Sulaiman, M. Basri, H. Reza, F. Masoumi, W. J. Chee, S E. Ashari, "Effects of Temperature, Time, and Solvent Ratio on the Extraction of Phenolic Compounds and the Anti Radical Activity of Clinacanthus Nutans Lindau Leaves by Response Surface Methodology”, Chemistry Central Journal, vol. 11 (54), 2017, pp.1-11.

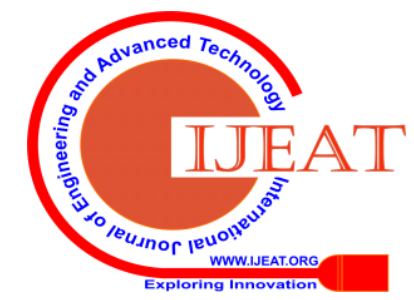


7. Vásquez, F. Edwin, A. V. Damian, "Agrotechnology A Preliminary Study for Cucurbita Moschata Duchesne ( Loche ) Crop Production under the Hydroponic Dutch Bucket System", Agrotechnology, vol. 6 (3), 2017, pp. 142-56. https://doi.org/10.4172/2168-9881.1000173.

8. S. B. Ivanka, S. Shiwakoti, C. L. Cantrell, V. D. Zheljazkov, T. Astatkie, V. Schlegel, T. Radoukova. "Hydrodistillation Extraction Kinetics Regression Models for Essential Oil Yield and Composition", 2019. Www. Mdpi.Com/ Journal/Molecules: Doi:10.3390/Molecules2405098624:1-17.

9. R. Jesús, B. Hernández-santos, E. Herman-lara, C. A. Gómez-aldapa, H. S. Garcia, C. E. Martínez-sánchez, "Effect of Some Variables on Oil Extraction Yield from Mexican Pumpkin Seeds", CyTA - Journal of

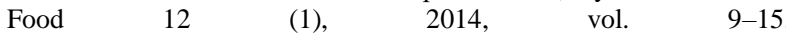
https://doi.org/10.1080/19476337.2013.777123

10. R. Leila, M. Chouaibi, R. M. Ojeda-amador, S. Gomez-alonso, M. D. Salvador, G. Fregapane, S. Hamdi, "Cucurbita Maxima Pumpkin Seed Oil, from the Chemical Properties to the Different Extracting Techniques", vol. 46 (2), 2018, pp. 663-69. https://doi.org/10.15835/nbha46211129

11. S. Ravi, S. Ahmed, "Pumpkin Seed Oil : An Alternative Medicine", International Journal of Pharmacognosy and Phytochemical Research, vol. 9 (2), 2017, pp. 223-27.

12. M. Srbinoska, N. Hrabovski, V. Rafajlovska, S. Sinadinović-Fišer, "Characterization of the Seed and Seed Extracts of the Pumpkins Cucurbita Maxima D. and Cucurbita Pepo L. from Macedonia”, Macedonian Journal of Chemistry and Chemical Engineering, vol. 31 (1), 2012, pp. 65-78.

13. J. Jiao, Z. Li, Q. Gai, X. Li, F. Wei, Y. Fu, W. Ma., "Microwave-Assisted Aqueous Enzymatic Extraction of Oil from Pumpkin Seeds and Evaluation of Its Physicochemical Properties, Fatty Acid Compositions and Antioxidant Activities", Food Chemistry, 147, 2014, pp. 17-24. https://doi.org/10.1016/j.foodchem.2013.09.079.

14. Venkatesa Prabhu. S, Baskar. R, Amare T. Adugna, Gizachew Assefa. $\mathrm{K}$, Amsalu Gosu. A, Effect of FE(II) Concentration on Bioleaching of Zinc from Sphalerite using Leptospirillum Ferriphilum: Kinetic Aspects, International Journal of Engineering and Advanced Technology, (2019), 9(1), pp. 1492-1498.

15. Venkatesa Prabhu. S, Girma Gonfa, Gizachew Assefa. K, Surafel M. Beyan and Ramesh. G, Biosolubilization of $\mathrm{Cr}(\mathrm{VI})$ from Tannery Sludge: Process Modeling, Optimization, Rate Kinetics and Thermodynamics Aspects, 'International Journal of Recent Technology and Engineering. (2019), 9(1), pp.1492-1498.

16. K. Raphael, C. Winini, A. Musengi, M. Mudyiwa, C. Nyambi, P. Muredzi, A. Malunga, "Proximate Composition of Pumpkin Gourd (Cucurbita Pepo) Seeds from Zimbabwe", International Journal of Nutrition and Food Sciences, vol. 3 (4), 2014, pp. 279-83. https://doi.org/10.11648/j.ijnfs.20140304.17

17. S. Mathangi, "A Study on Extraction of Oil from Pumpkin Seed Using Sun Drying and Hot Air Oven Drying", International Journal of Food Science and Nutrition, vol. 3 (1), 2018, pp. 34-36.

18. O. Jana, L. Misurcova, J. V. Ambrozova, R. Vicha, "Fatty Acids Composition of Vegetable Oils and Its Contribution to Dietary Energy Intake and Dependence of Cardiovascular Mortality on Dietary Intake of Fatty Acids" International Journal of Molecular Sciences, vol. 16 (4), 2015, pp. 12871-90. https://doi.org/10.3390/ijms160612871

19. L. Cardozo-Filhoa, R. Pazinato Cucoa, C. da Silva, "Simultaneous Extraction of Seed Oil and Active Compounds from Peel of Pumpkin (Cucurbita Maxima) Using Pressurized Carbon Dioxide as Solvent", The Journal of Supercritical Fluids, vol.143, 2019, pp. 8-15. https://doi.org/10.1016/j.supflu.2018.08.002

20. L. Stavros and J. Tsaknis, "Characterisation of Moringa Stenopetala Seed Oil Variety ' Marigat ' from Island Kokwa”, European Journal of Lipid Science and Technology, vol. 105, 2003, Pp. 23-31. https://doi.org/10.1002/ejlt.200390002

21. L. M. Yuliana, F. A. Natan, P. Widiyanti, D. Ikasari, N. Indraswati, F. E. Soetaredjo, "Extraction Of Neem Oil ( A Zadirachta Indica A . Juss ) Using N-Hexane And Ethanol : Studies Of Oil Quality”, Kinetic And Thermodynamic, vol. 3 (3), 2008, pp. 49-54.

22. M. Jafari, S. Amir, G. Hossein, M. Rahimmalek, "The Chemical Composition of the Seeds of Iranian Pumpkin Cultivars and Physicochemical Characteristics of the Oil Extract", Eur. J. Lipid Sci. Techno., vol. 114 (3), 2012, pp. 161-67. https://doi.org /10.1002/ejl t.20110 0102

23. H. Heeok, Chun-soo Kim, S. Maeng, "Effects of Pumpkin Seed Oil and Saw Palmetto Oil in Korean Men with Symptomatic Benign Prostatic Hyperplasia", Nutrition Research and Practice, vol. 3 (4), 2009, pp. 323-27. https://doi.org /10.4162/ nrp. 2009.3.4.323.

24. H. Taoufik, A. Farah, S. Lebrazi, M. Fadil, A. B. Alaoui, "Application of Response Surface Methodology for the Optimization of

Published By:

Blue Eyes Intelligence Engineering

\& Sciences Publication

(C) Copyright: All rights reserved.

\section{(01), 2018, pp. 50-54. https://doi.org/10.73 24/ JAPS.2018.8108}

(1) Extraction of Pistacia Lentiscus L. Essential Oil”,

25. G. Saidat, Olanipekun, M. Ibrahim, "Optimization and Extraction of Oil from Jatropha Seed Kernels" International Journal of ChemTech Research, vol. 9 (5), 2016, pp. 758-70.

26. P. Eshratabadi, M. H. Sarrafzadeh, H. Fatemi, M. Ghavami, "Enhanced Degumming of Soyabean Oil and Its Influences on Degummed Oil and Lecithin”, Iranian Journal of Chemical Engineering, vol. 5 (1), 2008, pp. 65-73. 